\title{
INSTRUMENTATION \& TECHNIQUES A behavior-genetic investigation of induction and
eduction times for halothane anesthesia
}

\author{
MERRILL F. ELIAS \\ Syracuse University, Syracuse, New York 13210 \\ and \\ BASIL E. ELEFTHERIOU \\ The Jackson Laboratory, Bar Harbor, Maine 04609
}

\begin{abstract}
Induction and recovery (eduction) times were measured for recombinant inbred strains (RI strains) of mice, their reciprocal $F_{1}$ hybrids and their progenitor strains. The resulting pattern of means for these groups indicated that two or more loci influence induction and eduction times. The strain distribution patterns were different for induction and eduction and for different dose levels of anesthetic. Strain differences in time to induce anesthetic effects and time to recover from anesthetic effects, as well as inadvertent use of varying anesthetic dose levels from study to study, may contribute to inconsistent results for studies of anesthetic effects on complex behavior.
\end{abstract}

There is an accumulating body of evidence which suggests that chronic exposure to halothane anesthesia results in decrements in cognition, learning, and perceptual abilities in humans and animals (Bruce, Bach, \& Arbit, 1974; Quimby, Aschkenase, Bowman, Katz, \& Chang, 1974). A number of studies indicated that a variety of inhalation anesthetics, including halothane, produce decrements in memory for events which most immediately precede anesthetic induction (Adam, 1973; Elias \& Simmerman, 1971; Essman \& Jarvik, 1961; Porter, 1972; Wimer, 1968). Presumably CNS depressant effects of inhalation anesthetics interferes with memory consolidation (Essman \& Jarvik, 1961).

In many memory consolidation experiments, animals have been anesthetized in small closed chambers containing a sponge or cotton soaked with a liquid anesthetic agent (e.g., Elias \& Simmerman, 1971; Essman \& Jarvik, 1961; Wimer, 1968). Among others, Cherkin (1968) and Eljas, Blenkarn, Simmerman, and Marsh (1971) have discussed the problems inherent in the administration of anestheties in this manner. These papers suggest that many of the inconsistent findings in the anesthetic-memory consolidation literature are related to failure to control anesthetic concentrations in the chamber and to the inadvertent use of varying doses of anesthesia from experiment to experiment. Cherkin

This research was supported in part by NIH Research Grant HD- 05523 (to BEE) from the National Institute of Child Health and Human Development and by a research grant from the United Health Services of North Carolina to MFE. Many thanks are extended to Dr. C. Douglass Blenkarn, Department of Anesthesiology, Duke University Medical Center, for his advise and assistance in the design of the anesthetic equipment.

The Jackson Laboratory is fully accredited by the American Association for the Accreditation of Laboratory Animal Care.
(1968) has pointed out a number of studies in which behavioral decrements may be related to the use of toxic doses of anesthesia.

In addition to inadvertent interstudy variations in anesthetic dose levels, a variety of strains and species of animals have been used in different studies. Thus, inconsistent findings which characterize this literature may reflect genotype-environment interactions with dose levels of anesthetic vapor. It is clear that strain differences exist with regard to complex behavioral responses to inhalation anesthetics (Elias \& Simmerman, 1971; Wimer, 1968), but few, if any, investigations have considered the more fundamental question of strain differences in time required for induction of anesthetic effects (induction time) and time required to recover from anesthetization (eduction time).

The existence of strain differences in induction and eduction time is a question of general methodological importance in behavior studies involving inhalation anesthetics. This is true for several reasons: (1) differences in induction and eduction times may be influenced by genotypic differences as well as environmental factors; (2) behavioral effects of inhalation anesthesia, particularly effects on memory registration are closely related to time required for induction and eduction (Wimer, 1968).

The finding that strain differences exist for induction and eduction time (Elias, et al., 1971) provides only the limited information that induction and eduction times are influenced by genotype. More refined behavior genetic analyses are nccessary to determine whether a single major gene is involved in halothane induction and eduction and, if so, to establish genetic linkage for these 


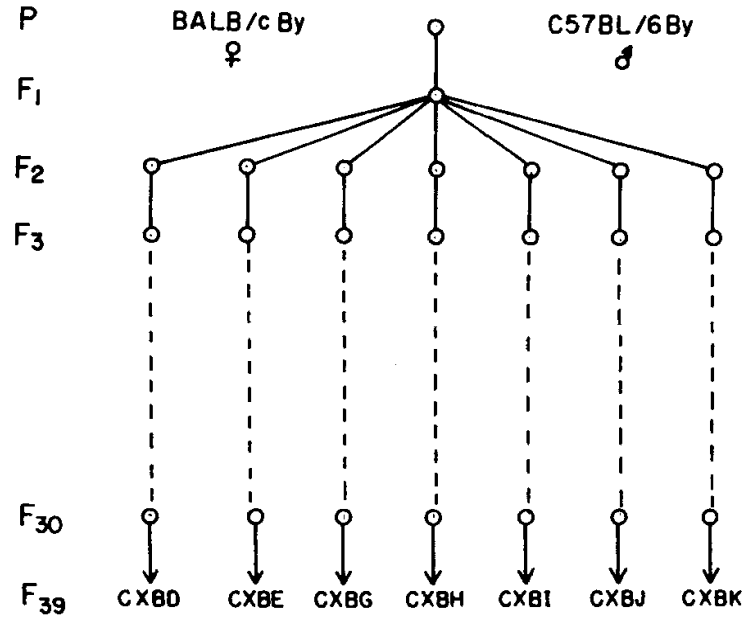

Figure 1. Schematic diagramm of breeding procedure.

phenomena. The present experiment was designed to achieve these objectives using genetic materials and a method of analysis revived and developed by Bailey (1971).

Results of the experiment have methodological implications for memory consolidation studies employing a variety of inhalation anesthetics, but response to halothane was of particular concern for several reasons. Halothane is the most widely used anesthetic for surgery in the United States (Quimby, Ashkinase, Bowman, Katz, \& Chang, 1974). Chronic exposure to halothane causes decrements in cognitive functioning and memory. Halothane has decided advantages for studies of memory consolidation because dose levels can be controlled and measured with precision (Elias et al., 1971).

\section{METHOD}

\section{The RI Strains}

The RI strains were derived by the crossing of two unrelated progenitor strains $(\mathrm{C} 57 \mathrm{BL} / 6 \mathrm{By}$ and $\mathrm{BALB} / \mathrm{cBy})$ and then maintaining of strains from the $F_{2}$ generation under a strict regimen of inbreeding. Figure 1 contains a schematic diagram of the breeding procedure. This procedure progressively fixes the chance recombination of genes as inbreeding continues and as full homozygosity is approached. The battery of strains resulting from this procedure may be considered a replicable recombinant population.

In addition to the RI strains, a battery of congenic lines was developed from the same initial crossing of C57BL/6By (B6) and $\mathrm{BALB} / \mathrm{cBy}(\mathrm{C})$ by means of a regimen of skin graft testing and backcrossing to $\mathrm{B} 6$ for at least 12 generations. The procedure and its use in combination with strain distribution patterns obtained with the RI strains has been described in considerable detail in previous reports (e.g., Bailey, 1971; Oliverio, Eleftheriou, \& Bailey, 1973a, b). Essentially, the procedure results in identification of a characteristic strain distribution pattern for each locus. Based on the strain distribution pattern, the appropriate congenic line can be selected and tests for linkage may be made by comparing the congenic line with the progenitor strains. In some instances, the strain distribution pattern does not provide evidence for a major gene effect. Rather, the presence of several overlapping groups indicates involement of two or more loci.

\section{Subjects}

A total of 227 mice were used. The animals were bred in MFE's laboratory from stock generously provided by Bailey. ${ }^{1}$ From birth, the animals were housed in groups of 2 to 4 and the day-night cycle was maintained at $10 \mathrm{~h}$ light and $14 \mathrm{~h}$ dark. Food and water were provided ad lib. During the experiment animals were housed in individual cages. Mean body weights within groups varied from 24 to $30 \mathrm{~g}$. Ages ranged from 2 to 5 months. In view of the necessity of testing all subjects from each RI strain on the same day, variability in age could not be avoided. Since age could not be precisely controlled, (1) correlations between age and induction and eduction times were determined; (2) analyses of covariance were performed with induction and eduction times adjusted for the regression of age and weight by means of analysis of covaraince (Wimer, 1962, pp. 578-618). There were $20 \pm 1$ mice in each group tested; one-half were female and one-half males.

\section{Apparatus}

The anesthetic chamber and procedure for anesthetization have been described in detail in a previous paper (Elias et al., 1971). Briefly, air was metered at $2.51 / \mathrm{min}$ through a flow meter and delivered to a Fluotic Mark IV halothane vaporizer containing the liquid anesthetic. The vaporizer was set to deliver concentrations of $2 \%, 3 \%$, and $4 \%$ halothane vapor to the anesthetic chamber.

A tight seal was created between the lid and the body of the chamber by means of a siliconized rubber gasket. Tubing at the top of the chamber provided an exhaust system which allowed airflow and served to stabilize the pressure within the chamber The Plexiglas chamber was rendered airtight by application of ethylene dichloride to the joints and tubing connections. Room temperature was monitored during the anesthetization procedure $\left(23 \pm 1^{\circ} \mathrm{C}\right)$. A Nakometer Nack Vondershmitt MT/672-2 infrared analyzer was used to confirm anesthetic concentrations within the chamber. Opening and closing the chamber to replace animals with 30 to $45 \mathrm{sec}$ between replacements resulted in variations of $.5 \%$ in anesthetic concentrations. Thus, effective concentrations of halothane for the three dose-level conditions were: $2 \pm .5 \%, 3 \pm .5 \%$, and $4 \pm .5 \%$. Tubing connections allowed the chamber to be flushed if these values were exceeded due to a build up of vapor resulting from continuous use of the system.

\section{Procedure and Design}

Mice were placed on a wire mesh platform $5 \mathrm{~cm}$ above the four tubes which delivered the anesthetic vapor to the base of the chamber at its four corners. The lid was placed on the chamber and time was recorded (in sec) from placement of the animal in the chamber until failure of righting reflexes. Failure of righting reflexes was defined as inability to stand and move with a normal gait on all four feet following slipping, staggering, and falling to the floor of the chamber. Ineffectual crawling and reflex movement occurred after loss of righting reflexes was observed. The animal was kept in the chamber $15 \mathrm{sec}$ after crawling and reflex movements ceased. It was removed after $15-\mathrm{sec}$ and time from removal to return of righting reflexes was determined.

A repeated measurement design was used so that each animal served as its own control. The three anesthetic concentrations were given to each animal on three consecutive days (between $1 \mathrm{pm}$ and $4 \mathrm{pm}$ ). Anesthetic concentrations (dose) and day of administration were counterbalanced within strains. The exact ordering of presentation within the constraints introduced by counterbalancing, was determined by a table of random numbers. 
Table 1

Means and Standard Deviations for All Groups in Seconds

\begin{tabular}{|c|c|c|c|c|c|c|c|c|}
\hline \multicolumn{3}{|c|}{$2 \%$} & \multicolumn{3}{|c|}{$3 \%$} & \multicolumn{3}{|c|}{$4 \%$} \\
\hline Group & Mean & SD & Group & Mean & SD & Group & Mean & SD \\
\hline \multicolumn{9}{|c|}{ Induction Scores } \\
\hline G & 110 & 33 & $\mathrm{C}$ & 44 & 221 & D & 27 & 5 \\
\hline $\mathbf{J}$ & 109 & 44 & $\mathrm{H}$ & 43 & 9 & $\mathrm{BCF}_{1}$ & 27 & 5 \\
\hline $\mathrm{CBF}$, & 106 & 38 & $\mathrm{CBF}$ & 42 & 9 & $\mathrm{H}$ & 26 & 5 \\
\hline & 106 & 26 & J & 41 & 7 & $\mathrm{C}$ & 26 & 3 \\
\hline $\mathrm{BCF}_{1}$ & 94 & 33 & D & 41 & 7 & $\mathrm{CBI}_{1}$ & 25 & 6 \\
\hline $\mathrm{E}$ & 90 & 33 & G & 41 & 7 & $\mathrm{G}$ & 25 & 4 \\
\hline D & 86 & 22 & $\mathrm{BCF}_{1}$ & 41 & 9 & I & 25 & 3 \\
\hline $\mathrm{K}$ & 86 & 19 & $\mathrm{E}$ & 41 & 7 & $\mathrm{~K}$ & 24 & 4 \\
\hline I & 80 & 44 & $\mathrm{~K}$ & 39 & 7 & $\mathrm{~J}$ & 24 & 4 \\
\hline H & 67 & 13 & I & 38 & 71 & $\mathrm{E}$ & 24 & 5 \\
\hline B6 & 62 & 18 & B6 & 32 & 6 & B6 & 18 & 4 \\
\hline \multicolumn{9}{|c|}{ Eduction Scores } \\
\hline $\mathrm{H}$ & 28 & 18 & D & 47 & 8 & $\mathrm{H}$ & 41 & 8 \\
\hline D & 24 & 6 & $\mathrm{H}$ & 32 & 17 & I & 36 & 16 \\
\hline $\mathrm{CBF}_{1}$ & 24 & 9 & B6 & 29 & 5 & $\mathrm{j}$ & 35 & 12 \\
\hline B6 ${ }^{1}$ & 22 & 16 & $\mathrm{CBF}$, & 28 & 13 & B6 & 33 & 6 \\
\hline $\mathrm{BCF}_{1}$ & 22 & 9 & I & 28 & 11 & $\mathrm{D}$ & 33 & 5 \\
\hline E & 21 & 9 & $\mathrm{~K}$ & 26 & 16 & $\mathrm{CBF}_{1}$ & 31 & 7 \\
\hline $\mathbf{K}$ & 20 & 8 & $\mathbf{J}$ & 25 & 13 & G 1 & 31 & 8 \\
\hline I & 20 & 6 & $\mathrm{E}$ & 24 & 11 & $\mathrm{BCF}_{1}$ & 30 & 6 \\
\hline C & 17 & 7 & $\mathrm{BCF}_{1}$ & 24 & 8 & E & 29 & 7 \\
\hline $\mathrm{G}$ & 16 & 7 & $\mathrm{G}$ & 22 & 9 & $\mathrm{~K}$ & 28 & 7 \\
\hline $\mathbf{J}$ & 15 & 11 & C & 18 & 9 & C & 25 & 7 \\
\hline
\end{tabular}

Note-Solid lines indicate means which are nonsignificantly different from each other.

\section{RESULTS}

The Strain by Halothane Concentration by Sex interaction was not statistically significant $(\mathrm{p}<.05)$. This was true with and without adjustment of scores for age and body weight by analyses of covariance.

The Strain by Halothane Concentration interaction was significant for induction and eduction scores $[\mathrm{Fs}(20,432) \geqslant 3.43, \mathrm{p}<.01]$. Table 1 shows induction and eduction times for all three dose levels of halothane averaging scores for males and females. Induction times decreased and eduction times increased with increasing concentrations of halothane vapor for all strains. The results of a posteriori probing tests are summarized as shown in Table 1. Several overlapping groupings of means were observed for contrasts involving induction and eduction at $2 \%$ halothane. Results were less complex for the $3 \%$ dose-level condition. The B6 strain exhibited a significantly shorter mean induction time than either of the $F_{1}$ hybrids and all other strains with the exception of CXBK and CXBI. For eduction at $3 \%$, the CSBD strain exhibited significantly longer times than all other strains and both hybrids.

For the 4\% halothane conditions, the B6 strain again exhibited a significantly shorter induction time than all other strains and hybrids. For eduction at $4 \%$, there were a number of groupings of means that were not different from each other. Comparisons of strain patterns for induction and eduction and for all dose levels reveals that the pattern of strain means differed considerably, although strain B6 exhibited the shortest induction scores consistently.

Within group correlations for induction and eduction times and correlations between scores obtained at the various dosage levels were low and statistically nonsignificant $(\mathrm{p}>.05)$.

Table 2 shows correlations between means tor the 11 groups (strains and hybrids) for induction and eduction times and for the anesthetic dose levels. Induction and eduction times were not significantly correlated at the $3 \%$ and $4 \%$ anesthetic dose levels, but a significant negative correlation was obtained for the $2 \%$ condition.

Body weight did not differ significantly among groups, but a significant $[\mathrm{F}(10,216)=5.39, \mathrm{p}<.01]$ difference among groups was observed for age. However, correlations between age and induction and eduction scores at the various anesthetic levels were low and nonsignificant. This is consistent with the finding that a similar pattern of means and $F$ ratios were observed when induction and eduction scores at all dose levels were adjusted for age by means of analysis of covariance.

\section{DISCUSSION}

Examination of the strain distribution pattern (group means) for induction and eduction measures and for all dose levels indicates involvement of at least two or more loci for each anesthetic concentration utilized. Thus, the possibility of a major gene effect is eliminated and a congenic line cannot be 
Table 2

Group Correlations Between Induction Times and Eduction Times and Between Percent Halothane Concentration for Induction and Eduction

\begin{tabular}{|c|c|c|c|c|c|}
\hline \multirow{2}{*}{\multicolumn{2}{|c|}{$\begin{array}{c}\text { Between Doses } \\
\text { for Induction } \\
\text { Comparison } r\end{array}$}} & \multirow{2}{*}{\multicolumn{2}{|c|}{$\begin{array}{c}\begin{array}{c}\text { Between Doses } \\
\text { for Eduction }\end{array} \\
\text { Comparison } r\end{array}$}} & \multirow{2}{*}{\multicolumn{2}{|c|}{$\begin{array}{l}\text { Between Induction } \\
\text { and Eduction Times } \\
\text { Level } \mathrm{r}\end{array}$}} \\
\hline & & & & & \\
\hline $2 \%$ and $3 \%$ & $.55^{*}$ & $2 \%$ and $3 \%$ & $.58 *$ & $2 \%$ & $-.62 * *$ \\
\hline $2 \%$ and $4 \%$ & .46 & $2 \%$ and $4 \%$ & .46 & $3 \%$ & -.17 \\
\hline $3 \%$ and $4 \%$ & $.75^{* *}$ & $3 \%$ and $4 \%$ & .49 & $4 \%$ & -.04 \\
\hline
\end{tabular}

$*_{p}<.05$, one-tailed test

${ }^{* *} p<.01$, one-tailed test

selected and tested for linkage.

The fact that the two reciprocal $F_{1}$ hybrids do not differ with respect to induction and eduction measures suggests that maternal effects, or maternal-paternal interactions, do not influence the induction and recovery of phenomenon. Furthermore, there is no evidence that the $F_{1}$ hybrids exceed either of the parental strains in resistance to anesthetic effects. Thus, heterosis does not appear to characterize response to halothane as ineasured in terms of induction and recovery.

The relatively low correlations between halothane induction and eduction times within groups reflects a restricted range of scores within groups (within strains and hybrids). The magnitude of the between-groups correlation coefficients indicates that a relatively small amount of the variance among means at one dose level can be predicted by examination of variance among group means at another. However, the presence of several significant group correlations indicates that at least some sets of common genes affect induction and eduction scores at different dose levels.

A significant negative correlation between induction and eduction scores was obtained for the $2 \%$ halothane condition (Table 2). Thus, the distribution of group means for eduction times tend to be the inverse of those observed for induction times. The presence of a significant negative group correlation (Table 2) suggests that some common sets of genes influence induction and eduction times at $2 \%$ halothane concentrations. However, the range of induction and eduction means is more restricted at the $3 \%$ and $4 \%$ halothane concentration conditions. This phenomenon may account, at least in part, for the low and nonsignificant correlations between induction and eduction at these dose levels.

The fact that different strain distribution patterns are obtained for different concentrations of halothane vapor provides evidence that observed induction and eduction times in response to varying levels of halothane are end points of a complex multigenic system which interacts with anesthesia dose levels. Complex genotype-environment interactions for fundamental and elementary behavioral responses to inhalation anesthetics may make it exceeding difficult to arrive at simple genetic models for more complex behavioral responses such as those involved in learning and cognitive performance.

There are several implications for studies of anesthetic effects on behavior in general. Results of experiments with a single strain of mice or a hybrid stock may not be expected to generalize to findings for other strains and stocks. This is particularly true under circumstances in which differences in strains and species from study to study are compounded by variations in effective levels of anesthesia. Exact control over anesthetic concentrations is impossible because of the many environmental factors which affect dose levels. However, investigators should take into consideration differences in induction and eduction times when they interpret effects of inhalation anesthetics on behavior. The latter generalization seems particularly pertinent to studies of memory consolidation in which induction and eduction times affect the degree to which amnesic effects are observed as well as the direction of influence (Porter, 1972; Wimer, 1968; Wimer \& Huston, 1974).

\section{REFERENCES}

Adams, N. Effects of general anesthetics on memory functions in man. Journal of Comparative and Physiological Psychology, $1973,83,293-305$.

Bailey, D. W. Recombinant inbred strains. Transplantation, $1971,11,325-327$.

Bruce, D. L., Bach, M. J., \& Arbit, Q. Trace anesthetic effects on perceptual, cognitive, and motor skills, Anesthesiology, 1974 , 40,453 .

Cherkin, A. Retrograde amnesia. Psychonomic Science, 1968 $13,255-256$

Eleftheriou, B. E., \& Bailey, D. W. Genetic analysis of plasma corticosterone in two inbred strains of mice. Journal of Endocrinology, 1972, 55, 415-420.

Elias, M. F., Blenkarn, D. G., Simmerman, S. J., \& Marsh, G. Administration of inhalation anesthetics to small animals. Behavior Research Methods \& Instrumentation, 1971, 3, 70-71.

Elias, M. F., \& Simmerman. S. J. Proactive and retroactive effects of diethylether on discrimination learning in DBA/2 and C57BL/6J mice. Psychonomic Science, 1971, 22, 299-301.

Essman, W. B., \& Jarvik, M. E. Improvement of retention for a conditioned response by ether anesthesia in mice. Psychopharmacologica, 1961, 2, 172-179.

Oliverio, A., Eleftheriou, B. E., \& Bailey, D. W. A gene influencing active avoidance performance in mice. Physiology and Behavior, 1973a, 11, 497-501.

Oliverio, A., Eleftheriou, B. E., \& Bailey, D. W. Exploratory activity: genetic analysis of its modification by scopolamine and amphetamine. Physiology and Behavior, 1973b, 10 , 893-899.

Porter, A. An analytic review of the effects of non-hydrogen-bonding anesthetics on memory processing. Behavior Biology, 1972, 7, 291-309.

Quimby, K. L., Aschkinase, L. J., Bowman, R. E., Katz, J, and Chang, L. W. Enduring learning deficits and cerebral synaptic malformation from exposure to 10 PPM Halothane, Science, 1974 (in press).

Wimer, R. E. Basis of a facilitative effect upon retention resulting from post-trial etherization. Journal of Comparative and Physiological Psychology, 1968, 65, 340-342.

Winer, B. J. Statistical principles in experimental design. New York: McGraw-Hill, 1962, Pp. 77-85, 578-618.

\section{NOTE}

1. Dr. Bailey's contribution of breeding stock is gratefully acknowledged.

(Received for publication September 13, 1974 revision received October 21,1974 .) 